\title{
The Bio-aerated Autoclaved Concrete: A New Solution for a Sustainable Product in the Building Sector
}

\author{
Tiziana Cardinale $^{1^{*}}$, Corradino Sposato ${ }^{2}$, Maria Bruna Alba ${ }^{1}$, Andrea Feo $^{1}$, Giorgio Leter ${ }^{3}$, Piero De Fazio ${ }^{1}$ \\ ${ }^{1}$ DTE-SAEN Centro Ricerche ENEA Trisaia, Rotondella (MT), Italy \\ ${ }^{2}$ DTE-BBC-TER Centro Ricerche ENEA Trisaia, Rotondella (MT), Italy \\ ${ }^{3}$ SSPT - TECS - BIORISC Centro Ricerche ENEA Casaccia Roma, Italy
}

Corresponding Author Email: tizcardina@ hotmail.it

https://doi.org/10.18280/ti-ijes.642-432

Received: 5 January 2020

Accepted: 3 March 2020

\section{Keywords:}

autoclavated aerated concrete, biocatalysts, aerating agent, yeast, green buildings

\begin{abstract}
This paper describes the results of an experimentation carried out at the ENEA laboratories of Trisaia Research Center concerning an innovative cellular concrete, covered by an international patent (patent WO/2019/049005): The Bio Autoclaved Aerated Concrete (BAAC). This innovative material preserves the characteristics of the commercial aerated Autoclavated concrete, but in its formulation the metallic aluminum powder does not cause the aeration process that determines the development of the porosity. On the contrary an organic agent is used as biocatalysts of hydrogen peroxide breakdown reactions, whereby molecular oxygen and water are obtained as reaction products. Many are the advantages deriving from the proposed new approach, considering the particular nature of the aerating agent: from the economic affordability, to a greater environmental sustainability thanks to simplification and safety of the entire production process. BAAC samples with a density of $500 \mathrm{~kg} / \mathrm{m}^{3}$ were produced and characterized by a physical and mechanical point of view, according to the technical standards. The results obtained are very similar to those of the AAC. The final product is therefore proposed as a green product, on which we are still working in order to include in the mix design components derived from by-products of other industrial processes.
\end{abstract}

\section{INTRODUCTION}

Nowadays the focus is to find alternatives materials in the construction sector for a greener environment.

Among all, Autoclaved Aerated Concrete (AAC) $[1,2]$ could represent a good eco-friendly solution, because it is a sustainable building material that is used to save energy and enhance the quality of buildings. It is porous, non-toxic, reusable, renewable and recyclable. It was invented in Sweden in the 1920s by the architect Johan Axel Eriksson, working with Professor Henrik Kreüger at the Royal Institute of Technology. He was looking for an alternative building material with properties similar to that of wood - good thermal insulation, solid structure and easy to work with - but without the disadvantage of combustibility, decay and termite damage. It provides a high degree of thermal insulation and considerable savings in material due to its porous and lightweight structure. Air-voids are entrapped in the mortar matrix by means of a suitable aerating agent, i.e. aluminum powder that is added to cement, lime, water and sand in order to generate hydrogen gas in the cement grout obtaining final products manufactured in a range of sizes and densities depending on the specific application. This allows reaching, in particular at low densities, a reduced thermal conductivity that is an advantage in terms of thermal insulation at ambient temperatures as well as an asset for resistance against fire, thanks to its homogeneous structure.

The lighter weight implies a better sustainability too assuming the benefit for less material outweighs potentially higher energy costs for production, which together with noncombustibility represents additional qualities of this material in the building industry.

\section{COMMERCIAL AAC PRODUCTION PROCESS}

Commercial autoclavated aerated cement (AAC) is a prefabricated cementitious material used in the building industry, consisting of a mixture of Portland cement, lime, metallic aluminum powder, water, silica sand powder and/or industrial waste (silica fumes, fly ash and slag), whose use can also lead to economic and energy savings as well as the possibility of recycling waste materials [3]. With the addition of aerating agents such as metal powders of $\mathrm{Al}$ and $\mathrm{Zn}$ it is possible to develop a chemical reaction whose direct consequence is to release molecular hydrogen $\left(\mathrm{H}_{2}\right)$, responsible for the specific porous structure of the AAC. During the subsequent autoclaving, at a pressure of 10 bar in saturated steam conditions for a period of 8-12 hours and at a temperature of about $190^{\circ} \mathrm{C}$, the lime, reacting with water and silica, forms a hydrated lime silicate (CSH), called Tobermorite by Heddle in 1880 :

$$
\mathrm{Ca}(\mathrm{OH})_{2}+\mathrm{SiO}_{2}+x \mathrm{H}_{2} \mathrm{O}=\mathrm{CaO} \cdot \mathrm{SiO}_{2} \cdot x \mathrm{H}_{2} \mathrm{O} \quad(\mathrm{CSH})
$$

Tobermorite $\left(\mathrm{Ca}_{5} \mathrm{Si}_{6} \mathrm{O}_{16}(\mathrm{OH})_{2} \cdot 4\left(\mathrm{H}_{2} \mathrm{O}\right)\right)$ is a crystalline material that gives the product a better mechanical resistance and makes it more stable than that formed at room temperature. 
The proportions of the components, mixed until a very fluid mixture is obtained, a semi-liquid "grout", vary according to the final density of the product. On average we generally have, according to weight percentages: silica sand $\left(\mathrm{SiO}_{2}\right) 38-42 \%$, Portland cement 5-15\%, Calcium oxide $(\mathrm{CaO}) 5-15 \%$, anhydrite $\left(\mathrm{CaSO}_{4}\right)$ 0-2\%, water $40-45 \%$.

At the end of the processing phase, a leavening agent is added to the mixture. At present, in commercial products, it consists of aluminium metal powder $(\mathrm{Al})$ between $0.5 \%$ and $0.8 \%$ with respect to the weight of dry cement. It reacts with the calcium hydroxide in alkaline environment $(\mathrm{pH}>12)$ and in presence of water, according to the following reaction:

$$
2 \mathrm{Al}+3 \mathrm{Ca}(\mathrm{OH})_{2}+6 \mathrm{H}_{2} \mathrm{O}=3 \mathrm{CaO} \cdot \mathrm{Al}_{2} \mathrm{O}_{3} \cdot 6 \mathrm{H}_{2} \mathrm{O}+3 \mathrm{H}_{2} \uparrow
$$

giving rise to a tri-calcium hexahydrate aluminate and molecular hydrogen.

As a result, there is the formation of bubbles inside the mixture, thus creating micro porosities that constitute the salient characteristic of the cellular concrete.

The action of the aerating medium produces an increase in the volume of the material from 1.5 to 5 times higher than the original volume of the cement grout. The leavening process stops when the material [4] reaches a solid consistency: the voids stabilize in the volume of material and the contained hydrogen is gradually released into the atmosphere, replaced by air.

The main technical data of the autoclaved aerated concrete reported in the technical sheets of the most widespread commercial products are:

Table 1. Physical parameters of conventional AAC

\begin{tabular}{cc}
\hline Physical parameters & Values \\
\hline Compressive strength $[\mathrm{MPa}]$ & $2 \div 8$ \\
\hline Density $\left[\mathrm{kg} / \mathrm{m}^{3}\right]$ & $300 \div 800$ \\
\hline Flexural strength $[\mathrm{MPa}]$ & $0.5 \div 1.25$ \\
\hline Static elastic modulus $\left[\mathrm{kN} / \mathrm{mm}^{2}\right]$ & $1.1 \div 3$ \\
\hline
\end{tabular}

\section{BAAC INVENTION}

\subsection{Bio innovation in the process}

The described process has various problems, first of all about the use of aluminium powder as the raw material of the final product.

In fact, aluminium powders can react quite easily with oxygen at room temperature: the smaller its particles (less than $100 \mu \mathrm{m})$, the greater the risk of explosion or fire. These powders are rarely uniform, since it is very likely to find aluminium particles of a size considered "safe" mixed with particles smaller than $100 \mu \mathrm{m}$. As a result, a possible risk of explosion is achieved together with a high combustion speed.

The search for an aerating agent [5-7] that avoids all these issues is therefore of high relevance for the producers who, moreover, could also reduce the safety-related costs.

The experimentation, which led to the development of a new eco-sustainable autoclavated aerated cement (called BAAC Bio-aerated autoclavated concrete) and subsequent international patent WO/2019/049005, completely removes these issues, due to the bio origin of the proposed aerating agent.

Initially, based on previous experience [8], laboratory reference samples were packaged, according to the formulation of the aerated product with aluminium powder (commercial method) [9].

Subsequently, a series of specimens were made with the innovative aeration method to compare the results of the physical parameters obtained by the two manufacturing processes.

A fundamental and characterizing aspect of the BAAC patent is the replacement of the conventional aerating medium (aluminium powder) with an enzyme catalase of organic origin (present in particular amounts in the cells of the common brewer's yeast Saccharomyces cerevisiae) and the hydrogen peroxide. The catalase enzyme catalyses a breakdown reaction of hydrogen peroxide, as a result of which molecular oxygen and water reaction products are obtained. If the reaction is carried out inside the cement mortar, the released oxygen will form the porosities that will increase the volume of the cementitious mass with the consequent reduction of the final density of the product.

The swelling of the cement occurs by means of a breakdown reaction of hydrogen peroxide, whose overall reaction, resulting from intermediate oxidation-reduction reactions, is as follows:

$$
2 \mathrm{H}_{2} \mathrm{O}_{2} \rightleftarrows \mathrm{O}_{2}+2 \mathrm{H}_{2} \mathrm{O}
$$

Catalase [10] is an enzyme synthesized by most living organ cells to control the harmful effects of oxidation of biomolecules due to aerobic cell metabolism or exposure to exogenous oxidizing species. Most of the catalases are composed of a protein tetramer coordinated by as many iron-containing porphyrin heme groups, which constitute the catalytic reaction centre capable of reacting with hydrogen peroxide.

The reaction is strongly exoenergetic and shows an enthalpy of decomposition of hydrogen peroxide at $25^{\circ} \mathrm{C}$, so it does not require any additional heat supply, unlike the industrial production process of the AAC which requires a supply of thermal energy to allow the reaction between aluminium and calcium hydroxide.

Preliminary feasibility tests were only qualitative and were carried out using only commercial cement (without adding aggregates and lime) to which the fresh yeast dissolved in water at a concentration of $10 \mathrm{~g} / \mathrm{L}$ was mixed, and the hydrogen peroxide was subsequently added (titrated at 35\%), in a ratio of 1:15 if compared to solution water. The entire compound was then further mixed to allow a uniform distribution of the parts.
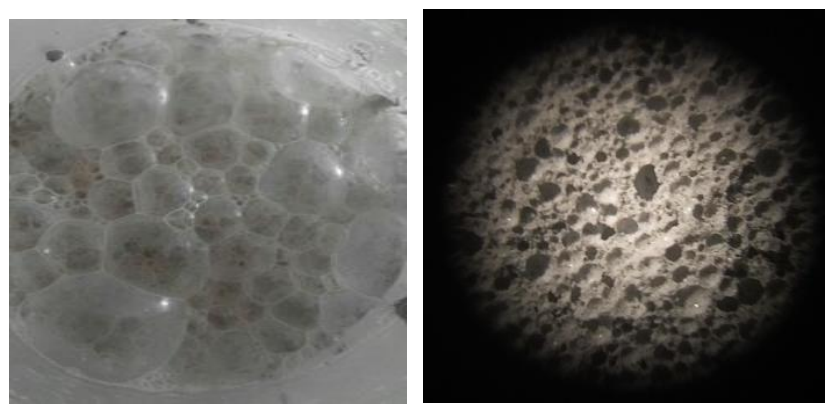

Figure 1. Aeration process of specimen made only by cement with yeast cells and $\mathrm{H}_{2} \mathrm{O}_{2}$ (on the left), consolidated specimen section (on the right)

Already during the mixing phase, it was possible to observe the formation of bubbles (Figure 1), with a consequent leavening of the mixture until the complete separation of $\mathrm{H}_{2} \mathrm{O}_{2}$. 
Once the growth was completed, the specimen was placed in an oven for 30 minutes at $50^{\circ} \mathrm{C}$ to accelerate the setting phenomenon. The test sample was then sectioned and observed under a stereoscopic microscope, indicating a formation of porosity in the specimen homogeneous both in distribution that size (Figure 1).

Once verified the feasibility, further experimental tests have been carried out to understand the relationship between the quantity of hydrogen.

The leavening was evaluated by measuring the increase in height of specimens prepared with the same formulation of the materials composing the grout (cement, silica, water and yeast) to which different percentages of hydrogen peroxide weight were added (Table 2, Table 3).

Table 2. Variation of $\mathrm{H}_{2} \mathrm{O}_{2}$ quantity used for leaving tests (Specimens 2-5)

\begin{tabular}{ccccc}
\hline Components [\%] & Test 2 & Test 3 & Test 4 & Test 5 \\
\hline Quartz & 34.87 & 34.83 & 34.78 & 34.73 \\
Cement & 23.42 & 23.38 & 23.35 & 23.32 \\
Water & 40.85 & 40.80 & 40.74 & 40.68 \\
Yeast & 0.29 & 0.29 & 0.29 & 0.29 \\
Hydrogen peroxide & 0.56 & 0.70 & 0.84 & 0.98 \\
\hline
\end{tabular}

Table 3. Variation of $\mathrm{H}_{2} \mathrm{O}_{2}$ quantity used for leaving tests (Specimens 6-9)

\begin{tabular}{ccccc}
\hline Components [\%] & Test 6 & Test 7 & Test 8 & Test 9 \\
\hline Quartz & 34.68 & 34.58 & 34.49 & 34.29 \\
Cement & 23.28 & 23.22 & 23.15 & 23.03 \\
Water & 40.62 & 40.51 & 40.40 & 40.17 \\
Yeast & 0.29 & 0.29 & 0.29 & 0.29 \\
Hydrogen peroxide & 1.12 & 1.40 & 1.67 & 2.22 \\
\hline
\end{tabular}

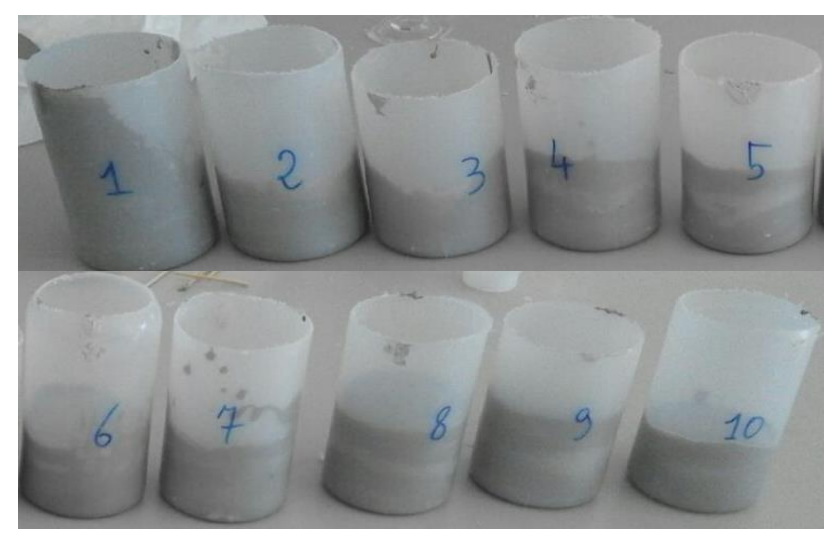

Figure 2. Cylindrical sample containers with same quantity of grout and variable amounts of $\mathrm{H}_{2} \mathrm{O}_{2}$

Then 200 grams of grout containing the same quantity of yeast were poured into the cylindrical plastic containers with a volume of $500 \mathrm{ml}$ (Figure 2), and variable amounts of hydrogen peroxide were added to the mixture.

As the concentration of hydrogen peroxide increases there is an increase in the final height of the cement sample. The variation in height increase of the specimen is always greater at the centre than at the wall of the container (Figure 3). It has also been observed that, during the leavening phase, the free surface of the specimens (the upper part) has a convex shape ("panettone" type), presumably due to the friction exerted by the walls of the container on the cement grout, in function of the viscosity of the mix, of the anisotropy of the cement-wall contact area and of the size of the free surface area.

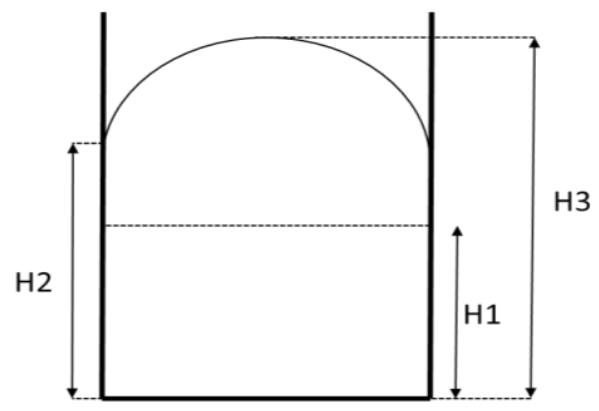

Figure 3. Graphic representation of the specimen

The height of the grout inside the container was determined both in the contact surface with the container and in the central surface, before the addition of $\mathrm{H}_{2} \mathrm{O}_{2}$ and at the end of the leavening process, as indicated below:

(1) initial height $(\mathrm{H} 1)$, on the wall before the addition of $\mathrm{H}_{2} \mathrm{O}_{2}$;

(2) final height $(\mathrm{H} 2)$, on the wall and at the end of the leavening;

(3) final height $(\mathrm{H} 3)$, evaluated at the center and at the end of the reaction.

The percentage increase in wall height is calculated with the formula $(\mathrm{H} 2-\mathrm{H} 1) / \mathrm{H} 1 * 100$, whereas the one in the centre is defined as $(\mathrm{H} 3-\mathrm{H} 1) / \mathrm{H} 1 * 100$. The percentage by weight of $\mathrm{H}_{2} \mathrm{O}_{2}$ at $35 \%$ is shown in the abscissa compared to the total weight of the used components.

The results are summarized in the graph (Figure 4), where each point (blue triangle the wall values, red circle the values at the centre) represents the arithmetic mean of three experimental tests.

For $\mathrm{H}_{2} \mathrm{O}_{2}$ values $0.28 \% \div 0.56 \%$, there isn't height increase. The maximum value of the curve is obtained for $2.2 \%$ by weight of $\mathrm{H}_{2} \mathrm{O}_{2}$ corresponding to a $115 \%$ increase in height, which is to a final double volume compared to the initial one.

Considering the volumetric expansion values obtained from previous tests on AAC specimens with aluminum powder, where the final volume obtained was of the order of $100 \%$ of the initial one, the replacement of the aerating medium with yeast and hydrogen peroxide has been shown to produce the same increase. The following image (Figure 5) show the size and distribution of porosity as a function of the different percentage content of $\mathrm{H}_{2} \mathrm{O}_{2}$ used.

The image shows a difference in the size and distribution of porosity: due to the higher peroxide concentration (sample C) the pore characteristics are not homogeneous. On the other hand, lower percentages of $\mathrm{H}_{2} \mathrm{O}_{2}$ (samples $\mathrm{A}$ and $\mathrm{B}$ ) show a more homogeneous distribution of porosities.

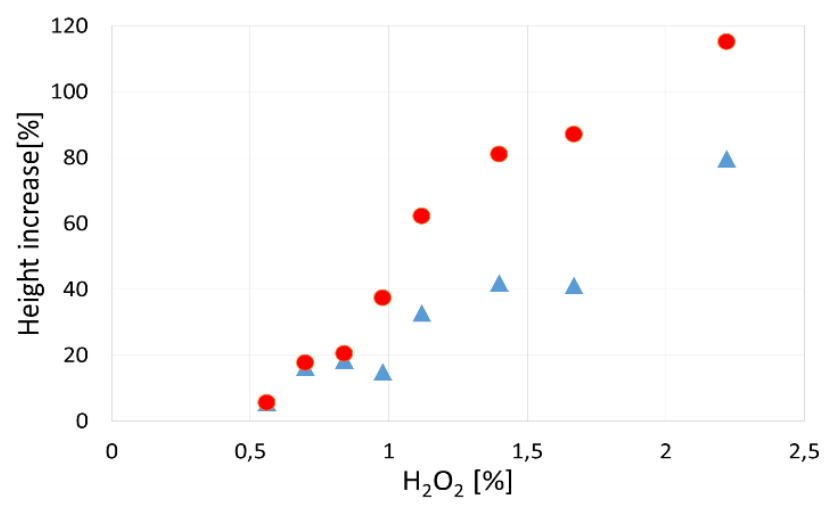

Figure 4. Test results with increasing percentages of $\mathrm{H}_{2} \mathrm{O}_{2}$ 


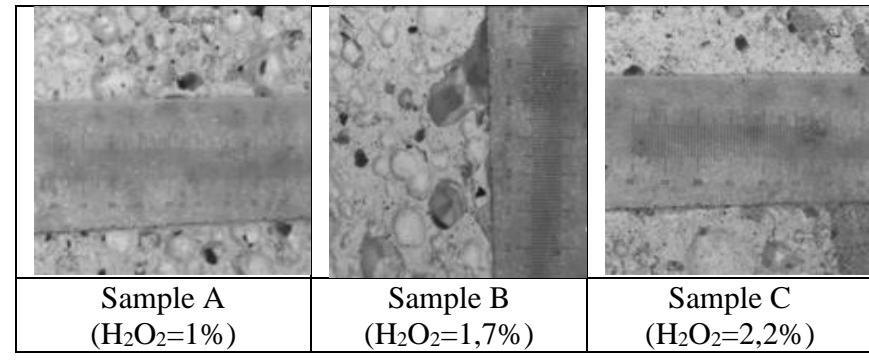

Figure 5. Microscopic analysis of the porosities of specimens made with different $\mathrm{H}_{2} \mathrm{O}_{2}$ percentages

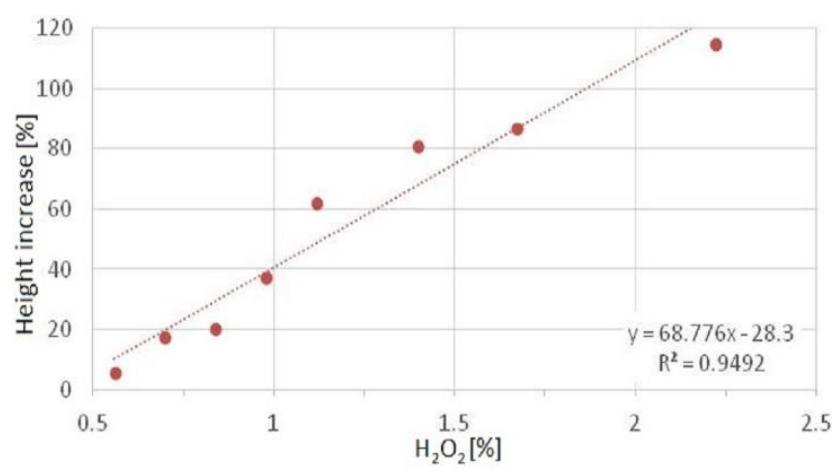

Figure 6. Line and regression coefficient: values relative to the central part of the specimen

Considering the values of the height reached at the center of the specimen, it was possible to observe how the growth process as a function of the quantity of hydrogen peroxide follows a linear trend, with a correlation coefficient $\left(\mathrm{R}^{2}\right)$ close to unity (Figure 6).

\section{MATERIALS AND METHODS}

Considering as reference the density value of $500 \mathrm{~kg} / \mathrm{m}^{3}$, common to many AAC products on the market, a series of tests were carried out in order to define the mix design with the best qualities of density parameters, thermal conductivity and compressive strength:

- Sand: Quartz $99.2 \%$ purity $\left(0.45 \%\right.$ of $\left.\mathrm{Al}_{2} \mathrm{O}_{3}\right)$, average diameter smaller than $10 \mu \mathrm{m}$ (Silverbond SA600, Sibelco Italia).

- Cement: CEM II A LL as UNI EN 197-1:2001.

- Water: network aqueduct.

- Lime: hydrated, $\mathrm{CaO} \geq 85 \%$ as EN 459-1: 2010 standard (Industria Calce Casertana srl).

- Yeast: freeze-dried yeast (Auchan).

- Hydrogen peroxide: 130 volumes in water solution (A. Sella s.r.l. pharmaceutical chemical lab).

Table 4. Components of BAAC mix design

\begin{tabular}{cc}
\hline Physical parameters & Values [\%] \\
\hline Silica sand & 34.90 \\
\hline Portland cement & 23.25 \\
\hline Water & 40.70 \\
\hline Yeast & 0.29 \\
\hline Hydrogen peroxide & 0.86 \\
\hline
\end{tabular}

After some preliminary tests it was verified that the hydrated lime component did not involve substantial changes in terms of height and porosity for the purposes of the quality of the final BAAC product [11], therefore it was no longer included in the successive tests, with positive consequences both in economic and environmental terms.

This process comprises the following steps:

(1) sand and cement are placed in an appropriate container and dry mixed for 1 minute;

(2) the yeast was dissolved in water at a temperature of $40^{\circ} \mathrm{C}$ and further mixed for about 1 minute;

(3) the mixture containing the yeast is gradually added to the solid mixture and the resulting grout is mixed by hand for 3 minutes;

(4) further mixing of the grout by an electric mixer for a total time of 5 minutes;

(5) $\mathrm{H}_{2} \mathrm{O}_{2}$ is added and mixed by hand for 30 seconds;

(6) the permutation reaction of the $\mathrm{H}_{2} \mathrm{O}_{2}$ present in the grout takes place at room temperature and is completed within 15-20 minutes after the addition of $\mathrm{H}_{2} \mathrm{O}_{2}$ with a consequent volume increase of the of about $80 \%$ if compared to the initial one;

(7) the resulting grout is placed inside the mould, where it remains for 3 hours at room temperature for leavening and completion of the setting phase. In this passage, cubic geometry formwork was used (Figure 7), containing $0.5 \mathrm{~kg}$ of dry weight of the solid materials composing the grout.
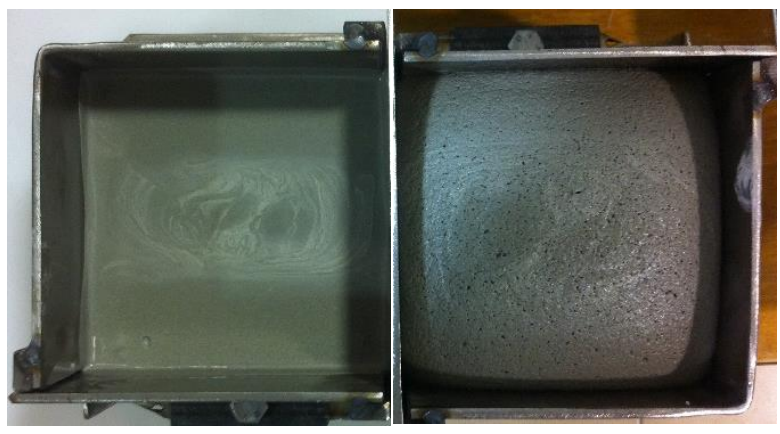

Figure 7. Specimens before and after leaving phase

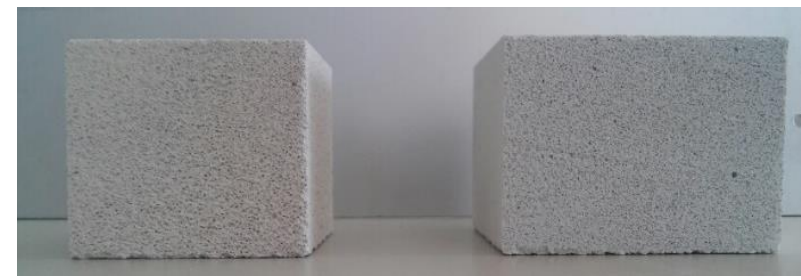

Figure 8. BAAC sample and AAC sample

The image (Figure 8) shows in the BAAC specimen (on the left) a uniformly distributed porosity in the volume in accordance with that of the AAC specimen of same density.

\section{RESULTS AND DISCUSSION}

Experimental tests were performed to investigate physical, thermal and mechanical properties of manufactured specimens. The characterization of BAAC sample was determined for the density according to the UNI EN 678: 1994 standard [12], for the compressive strength according to UNI EN 679: 2005 standard [13] and for thermal conductivity according to UNI EN 12664:2002 [14]. 
Table 5. Physical parameters of BAAC samples compared with commercial AAC reproduced in laboratory

\begin{tabular}{ccc}
\hline Physical parameters & $\begin{array}{c}\text { BAAC } \\
\text { values }\end{array}$ & $\begin{array}{c}\text { AAC reference } \\
\text { values }\end{array}$ \\
\hline Density $\left[\mathrm{kg} / \mathrm{m}^{3}\right]$ & 500 & 550 \\
\hline Compressive strength $[\mathrm{MPa}]$ & 3 & 3 \\
\hline Conductivity $[\mathrm{W} / \mathrm{mK}]$ & $\leq 0.118$ & $\leq 0.128$ \\
\hline
\end{tabular}

Data show that the compressive strength of the two types of specimen is the same, but with the same water/solids ratio of 0.7, the densities are different: lower for BAAC and higher for AAC. This means that the BAAC with the same mechanical performance (compressive strength) has a lower density and a greater insulating power (thermal conductivity $\lambda$ ) and therefore, in general, is more advantageous from a commercial point of view.

In the following Figure 9 you can see an exemplificative diagram of compressive stress vs deformation, which is qualitatively the same for all the tested BAAC specimens. The trend of the curve is typical of the behavior of a material that reaches the maximum breaking load without plastic deformations [15].

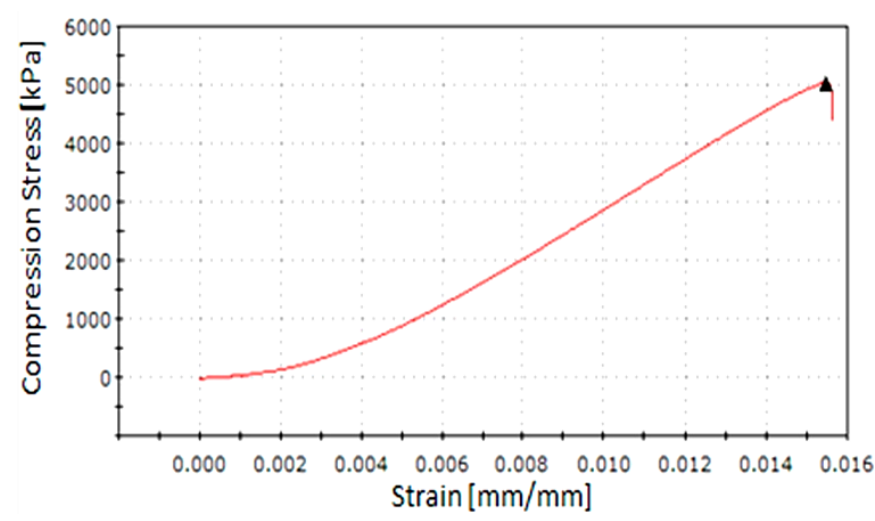

Figure 9. BAAC compressive stress vs deformation diagram

The morphological characterization of BAAC specimens with a density of $500 \mathrm{~kg} / \mathrm{m}^{3}$ has been made by an optical microscope Olympus mod. SZ 40 [16] and it shows that the shape of the pores is spherical, with a homogeneous distribution in both materials.

\section{CONCLUSIONS}

This paper describes the experimental activity carried out at the laboratories of ENEA Trisaia DTE-SAEN and ENEA Casaccia SSPT-TECS-BIORISC aimed at testing some innovative modifications in the manufacturing process of autoclaved aerated concrete, in particular the replacement of the aerating agent. In the described innovative process an enzyme of organic origin, present in the yeast cells, promotes the breakdown reaction of the hydrogen peroxide from which molecular oxygen is released that causes cement process aeration [17, 18]. The results of the comparative analyses between the innovative BAAC and the commercial AAC showed that, with the same performance, the process obtained through the organic aeration medium represents a valid alternative to the conventional process, based on these considerations:
(1) Simplification of the industrial process and improvement of safety.

The production of AAC is based on the use of aluminium powder as an aerating agent, whose storage and handling require stringent safety rules to contain the risk factors due to its high reactivity with oxygen even at room temperature. As known, in fact, aluminium dust, when exposed to the air, can form the $\mathrm{Al}_{2} \mathrm{O}_{3}$ oxide (alumina) with a strongly exothermic reaction that, if not controlled, can cause fires with potentially explosive effects. All operations concerning the storage, handling and manipulation of the material must be carried out in compliance with the safety conditions set out in the ATEX guidelines (ATmospheres EXploisible) with consequent increase in management costs related to safety. Moreover, the modest concentration of $\mathrm{H}_{2} \mathrm{O}_{2}$ in use and the complete absence of pathogenic elements of the yeast suggest a safe use in terms of bio-safety both in working environments and for end users.

(2) Environmental sustainability.

The elimination of aluminium powder from the BAAC manufacturing process is highly advantageous in terms of environmental impact [19]. The production of yeast in the Saccharomyces cerevisiae species occurs in bioreactors fed mainly with waste materials from the food processing or agroforestry industry (in general biomass with high carbohydrate content) and then inserted into the reuse cycle of the raw materials used in other industrial processes, mainly those based on fermentation. Furthermore, as regards production that does not require a food grade, yeast production and final product control processes can still be reduced considerably.

Another advantage in terms of costs and sustainability of the production process attributable to BAAC concerns the leavening phase that occurs at room temperature in contrast to the similar process that takes place in commercial AAC where it is necessary to maintain the grout at a controlled temperature variable between $40^{\circ} \mathrm{C}$ and $80^{\circ} \mathrm{C}$ for the whole leavening process.

(3) Improvement of physical properties.

The tests carried out in the laboratory have shown that, with the same ratio of water-solids of 0.7 , BAAC has a density lower than that of $\mathrm{AAC}$ and absolute values of mechanical resistance substantially similar in numerical terms but relatively better in BAAC if considering the lower density. The lower density obtained in BAAC specimens compared to AAC ones determines better performance in terms of thermal insulation, the creation of lighter products as required in the earthquakeresistant building and, finally, lower transport costs per volume unit.

(4) Economic aspect.

A final consideration must be made in relation to the economic aspect, i.e. the production costs resulting from the cost of raw materials used in the manufacture of AAC and BAAC. Given the market prices of the components and their relative amounts necessary for the manufacture of AAC and BAAC, the total production costs considered gross of the production energy give BAAC an economic advantage.

In conclusion, on the basis of the first results obtained, the innovative patented process for the realization of BAAC appears to be advantageous with respect to the conventional production process of the commercial typology [20]. The experimentation will continue for the optimization of physical and mechanical specifications, also with the possible use of alternative materials to maximize performance in terms of lightness, mechanical strength and insulating power. 


\section{REFERENCES}

[1] Hellers Bo, G., Schmidt Bo, R. (2011). Autoclaved Aerated Concrete (AAC)-the story of a low-weight material. Materials of 5th International Conference on Autoclaved Aerated Concrete-Securing Sustainable Future, Bydgoszcz, Poland, pp. 63-68.

[2] Vats, F. (2019). Autoclaved Aerated Concrete: Versatile building material. International Journal of Advance Research, Ideas and Innovation in Technology, 5(3): 2092-2098.

[3] Aidan, A., Shareefdeen, Z., Bogdanov, B., Markovska, I., Rusev, D., Hristov, Y., Georgiev, D. (2009). Preparation and properties of porous aerated concrete. НАУЧНИ ТРУДОВЕ НА РУСЕНСКИЯ УНИВЕРСИТЕТ, 48(9): 24-28.

[4] Narayanan, N., Ramamurthy, K. (2000). Structure and properties of aerated concrete: A review. Cement \& Concrete Composite, 22(5): 321-329. https://doi.org/10.1016/S0958-9465(00)00016-0

[5] Zanette, L. (2011). Studio dell'influenza di diversi agenti aeranti ed antischiuma sull'inglobamento d'aria. Tesi di laurea in Ingegneria Chimica - Università degli studi di Padova Facoltà di Ingegneria.

[6] Tang Van, L., Vu Kim, D., Ngo Xuan, H., Vu Dinh, T., Bulgakov, B., Bazhenova, S. (2019). Effect of aluminium powder on light-weight aerated concrete properties. E3S Web of Conferences, 97: 1-10. https://doi.org/10.1051/e3sconf/20199702005

[7] Van Boggelen, D.R. (2011). Safe aluminium dosing in AAC plants. 5th Int. Conf. on Autoclavated Aerated Concrete, Aircrete Europe B.V., Netherlands, pp. 40-45.

[8] Alba, M.B., Cardinale, T., De Fazio, P., Lista, G.F., Sposato, C. (2016). Tests for the characterization of fiber reinforced autoclaved aerated concrete. ECCM17 - 17th European Conference on Composite Materials Munich, Germany, pp. 1-8.

[9] UNI EN 771-4. (2015). Elementi di calcestruzzo aerato autoclavato per muratura.

[10] Chelikani, P., Ramana, T., Radhakrishnan, T.M. (2005). A Repertoire of unusual features. Indian Journal of Clinical Biochemustry, 20(2): 131-135. https://doi.org/10.1007/BF02867412

[11] Ekaputri, J.J., Triwulan, T., Brahmantyo, D., Nasir, S.,
Raja, F. (2013). Optimization of pressure and curing time in producing autoclaved aerated concrete. 6th Civil Engineering Conference in Asia Region: Embracing the future trough Sustainability, pp. 50-56. https://doi.org/10.13140/2.1.2505.6964

[12] UNI EN 678-1994. Calcestruzzo aerato autoclavato (AAC). Determinazione della massa volumica a secco.

[13] UNI EN 678-1994. Calcestruzzo aerato autoclavato (AAC). Determinazione della massa volumica a secco.UNI EN 679-2005. Determinazione della resistenza a compressione del calcestruzzo aerato autoclavato.

[14] UNI EN 12664:2002. Thermal performance of building and products - Determination of thermal resistance by means of guarded hot plate and heat flow meter methods - Dry and moist products of medium and low thermal resistance.

[15] Mazur, W., Drobiec, Ł., Jasiński, R. (2018). Effects of specimen dimensions and shape on compressive strength of specific autoclaved aerated concrete. Ce Papers, 2: 541-556.

[16] Schober, G. (2011). Porosity in autoclaved aerated concrete (AAC): A review on pore structure, types of porosity, measurement methods and effects of porosity on properties. 5th International Conference an Autoclaved Aerated Concrete, pp. 351-359.

[17] Sayed Khalil, E.A. (2019). Impact of autoclaved aerated concrete (AAC) on modern constructions: a case study in the New Egyptian Administrative Capital. Thesis Masters of Science in Construction Engineering B.Sc. in Architectural Engineering.

[18] Farhana, S., Makwana, A.H., Pitroda, J., Vyas, C.M. (2014). Aerated autoclaved concrete (AAC) blocks: novel material for construction industry. IJARESM, International Journal of Advanced Research in Engineering, Science \& Management, 1(2): 21-32.

[19] Rathi, S.O., Khandve, P.V. (2016). Cost effectiveness of using AAC blocks for building construction in residential building and public buildings. IJRET, International Journal of Research in Engineering and Technology, 5(5): 517-520.

[20] Catalogo

GASBETON. https://www.gasbeton.it/gasbeton/, accessed on 26 December 2019. 